\title{
Fast-track laparoscopic surgery: A better option for treating colorectal cancer than conventional laparoscopic surgery
}

\author{
YERLAN TAUPYK* ${ }^{*}$ XUEYUAN CAO*, YINQUAN ZHAO, CHAO WANG and QUAN WANG \\ Department of Gastric and Colorectal Surgery, First Hospital of Jilin University, Changchun, Jilin 130021, P.R. China
}

Received July 24, 2014; Accepted April 8, 2015

DOI: $10.3892 / 01.2015 .3166$

\begin{abstract}
Fast-track surgery (FTS), a multimodal rehabilitation technique, has been recommended as surgical therapy for colorectal cancer. The objective of the present study was to compare the outcomes of FTS and conventional laparoscopic surgery. This study was a blinded randomized trial. A total of 70 patients with colorectal cancer were divided into two groups and underwent laparoscopic colorectal resection. The FTS group consisted of 31 patients and the control group consisted of 39 patients. Protocols for the treatment of the FTS group included skipping pre-operative mechanical bowel preparation, early restoration of diet and early post-operative ambulation. Outcome measures, length of hospital stay, post-operative surgical stress response [C-reactive protein (CRP)] and post-operative complications were compared between the two groups. The average length of total hospital stay for the FTS and the control groups was $5.9 \pm 0.8$ and $10.9 \pm 1.3$ days, respectively $(\mathrm{P}<0.05)$, and the length of post-operative hospital stay for the FTS and control group was $4.3 \pm 0.8$ and $8.0 \pm 1.1$ days, respectively. $(\mathrm{P}<0.05)$ First flatus time for the FTS and control groups was $1.6 \pm 0.8$ and $2.5 \pm 0.9$ days, respectively $(\mathrm{P}<0.05)$. Defecation time for the FTS and control groups was $2.2 \pm 0.7$ and $4.5 \pm 0.7$ days, respectively $(\mathrm{P}<0.05)$. The time to restoration of a solid diet also showed a significant difference between the FTS and control groups $(1.1 \pm 0.3$ vs. $3.6 \pm 0.9$ days; $\mathrm{P}<0.05)$. Following surgery, due to post-operative surgical stress, the two groups CRP levels increased significantly, but the levels of the FTS group were lower than those of the conventional control group $(\mathrm{P}<0.05)$. There was no difference in post-operative complications between the FTS and control groups. This study confirms that FTS shortens hospital stay and accelerates the recovery of bowel function without increase of post-operative complications. FTS is safe, improves post-operative recovery and
\end{abstract}

Correspondence to: Professor Quan Wang, Department of Gastric and Colorectal Surgery, First Hospital of Jilin University, 71 Xinmin Street, Changchun, Jilin 130021, P.R. China

E-mail: wangquan-jlcc@hotmail.com

*Contributed equally

Key words: fast-track surgery, laparoscopic surgery, colorectal cancer, randomized trial is a better option than conventional laparoscopic surgery for treating colorectal cancer patients.

\section{Introduction}

Fast-track surgery (FTS) was first proposed in a study by Kehlet et al, which focused on using a variety of measures to control a patient's perioperative pathophysiological reaction, to reduce surgical stress and complications, to enhance post-operative rehabilitation and to improve prognosis (1). FTS can be considered as multimodal perioperative care. The main components include simplified bowl preparation, skipping the routine mechanical enema, using epidural anesthesia and analgesia, laparoscopic surgery, early removal of the nasogastric and drainage tubes, and early post-operative activities.

Randomized controlled trials and meta-analyses have shown that the skipping of the routine mechanical enema, the use of epidural anesthesia and analgesia, the early removal of the nasogastric tube and the early post-operative daily activities, which are components of FTS, do not increase the incidence of post-operative colorectal surgery complications, such as anastomotic leakage, post-operative intestinal obstruction and abdominal infection (2-4). However, few physicians have adopted FTS in clinical practice in China. One reason for this may be that Chinese physicians are waiting for convincing evidence that FTS is better than conventional laparoscopic surgery $(5,6)$. The aforementioned randomized controlled trials and meta-analyses are mostly based on patients in Europe and America. Thus, the present randomized controlled study was conducted on Chinese patients in mainland China.

\section{Subjects and methods}

Subjects. A randomized blinded study was conducted (trial number, NCT01969591). All clinical data was collected from 70 cases of colorectal cancer patients who were admitted to the Department of Gastrointestinal Surgery, First Hospital of Jilin University (Changchun, Jilin, China) between January 2011 and July 2012, and met the selection criteria listed in Table I. Subsequent to obtaining written informed consent, the patients were randomly divided into two groups. Post-operative observations and surgical outcomes were compared. The efficacy of FTS applied in colorectal cancer was evaluated. The study protocol was approved by the Ethics Committee of the First Hospital of Jilin University. 
Methods. The 70 patients with colorectal cancer were divided into two groups, the FTS group (31 cases) and the control group (39 cases), according to the perioperative treatment. The differences in perioperative care between the two groups are listed in Table II. Patient age, gender, basic disease(s), tumor-node-metastasis stage (7), surgical approach, duration of surgery and blood loss volume are listed in Table III.

Statistical analysis. The SPSS 16.0 statistical software package (SPSS, Inc., Chicago, IL, USA) was used to process the data, recorded as mean \pm standard deviation, and processed using a t-test for two independent samples. Count data was compared using the $\chi^{2}$ test. $\mathrm{P}<0.05$ was used to indicate a statistically significant difference.

\section{Results}

Hospital stay duration. The average length of total hospital stay for the FTS and control groups was $5.9 \pm 0.8$ and $10.9 \pm 1.3$ days, respectively $(\mathrm{P}<0.05)$, and the length of post-operative hospital stay was $4.3 \pm 0.8$ and $8.0 \pm 1.1$ days, respectively $(\mathrm{P}<0.05)$. First flatus time for the FTS and control groups was $1.6 \pm 0.8$ and $2.5 \pm 0.9$ days, respectively $(\mathrm{P}<0.05)$, while defecation time was $2.2 \pm 0.7$ and $4.5 \pm 0.7$ days, respectively $(\mathrm{P}<0.05)$. The time to restoration of a solid diet also exhibited a significant difference between the FTS and control groups $(1.1 \pm 0.3$ vs. $3.6 \pm 0.9$ days; $\mathrm{P}<0.05)$ (Fig. 1$)$.

Post-operative analgesic adminstration. In the first 3 post-operative days, the results for the FTS group show that 18 patients $(58.1 \%)$ did not use analgesics, whereas 5 patients $(16.1 \%)$ used analgesics once, 6 patients (19.4\%) used them twice and 2 patients (6.5\%) used them 3 times. In the first 3 post-operative days for the control group, 21 patients $(53.9 \%)$ did not use analgesics, whereas 9 patients $(23.1 \%)$ used analgesics once, 7 patients $(18.0 \%)$ used them twice and 2 patients $(5.1 \%)$ used them 3 times. The use of analgesic between the two groups showed no significant difference $(\mathrm{P}>0.05)$.

$C$-reactive protein levels. The pre-operative C-reactive protein (CRP) levels between the FTS $(1.4 \pm 0.9 \mathrm{mg} / \mathrm{l})$ and control $(1.4 \pm 0.9 \mathrm{mg} / \mathrm{l})$ groups exhibited no significant difference (P>0.05). On post-operative day 1, the CRP level of the FTS group was high, but lower than the CRP level in the control group (35.4 $\pm 7.5 \mathrm{mg} / \mathrm{l}$ vs. $40.6 \pm 11.9 \mathrm{mg} / \mathrm{l} ; \mathrm{P}<0.05)$ (Fig. 2).

Post-operative complications. Two cases of intestinal obstruction $(5.1 \%)$ were observed in the control group, but there were no cases of anastomotic leakage or wound infection. One case in the FTS group experienced wound infection (3.3\%). The incidence of complications between the FTS and control groups showed no significant difference ( $\mathrm{P}>0.05)$ (Table IV).

\section{Discussion}

A number of studies documenting the efficacy of laparoscopic surgery have been performed since its advent in the early 1990's. Minimally invasive laparoscopic surgery aids in reducing post-operative pain, the incidence of hemorrhage, wound infections and inflammation. Fast-track laparoscopic

Table I. Inclusion and exclusion criteria.

Inclusion criteria Exclusion criteria

Age $\leq 75$ years

Good nutrition and no systemic infection

Elective laparoscopic surgery
Age $>75$ years

Malnutrition or an organ system infection

Associated with obstruction, bleeding, emergency surgery or surgical intervention Tumor with extensive metastasis Prior to surgery, patient was fasting, underwent gastrointestinal decompression and received nutritional support Previous history of abdominal surgery

Patient had previously undergone gastrostomy

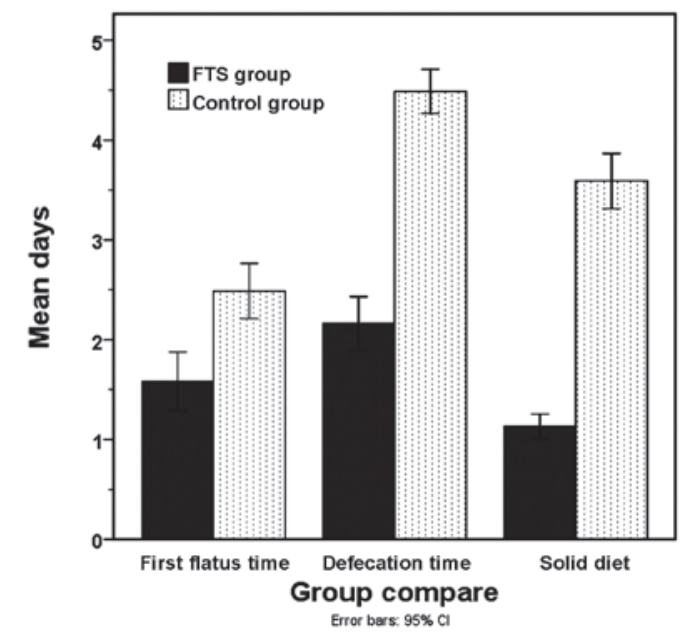

Figure 1. Comparison of post-operative recovery levels, as indicated by first flatus time, defecation time and time to resumption of a solid diet. FTS, fastr-track surgery.

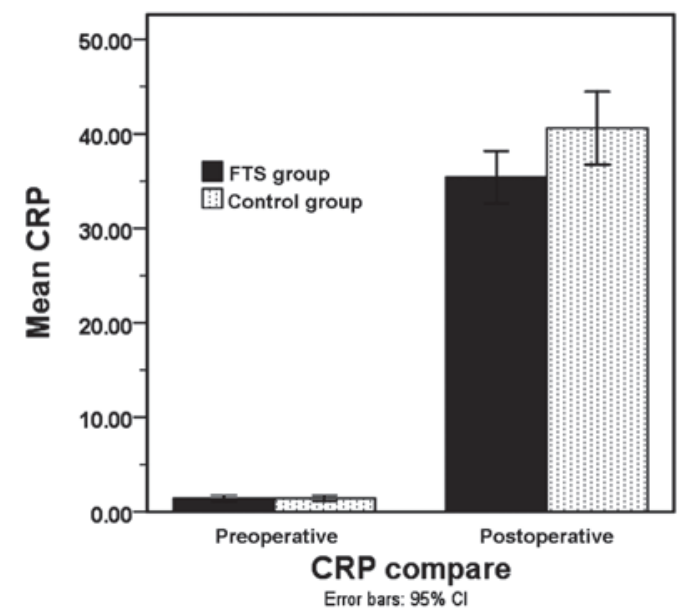

Figure 2. Comparison of stress index [C-reactive protein (CRP) level] between the two groups pre-operatively and post-operatively. FTS, fast-track surgery; CI, confidence interval. 


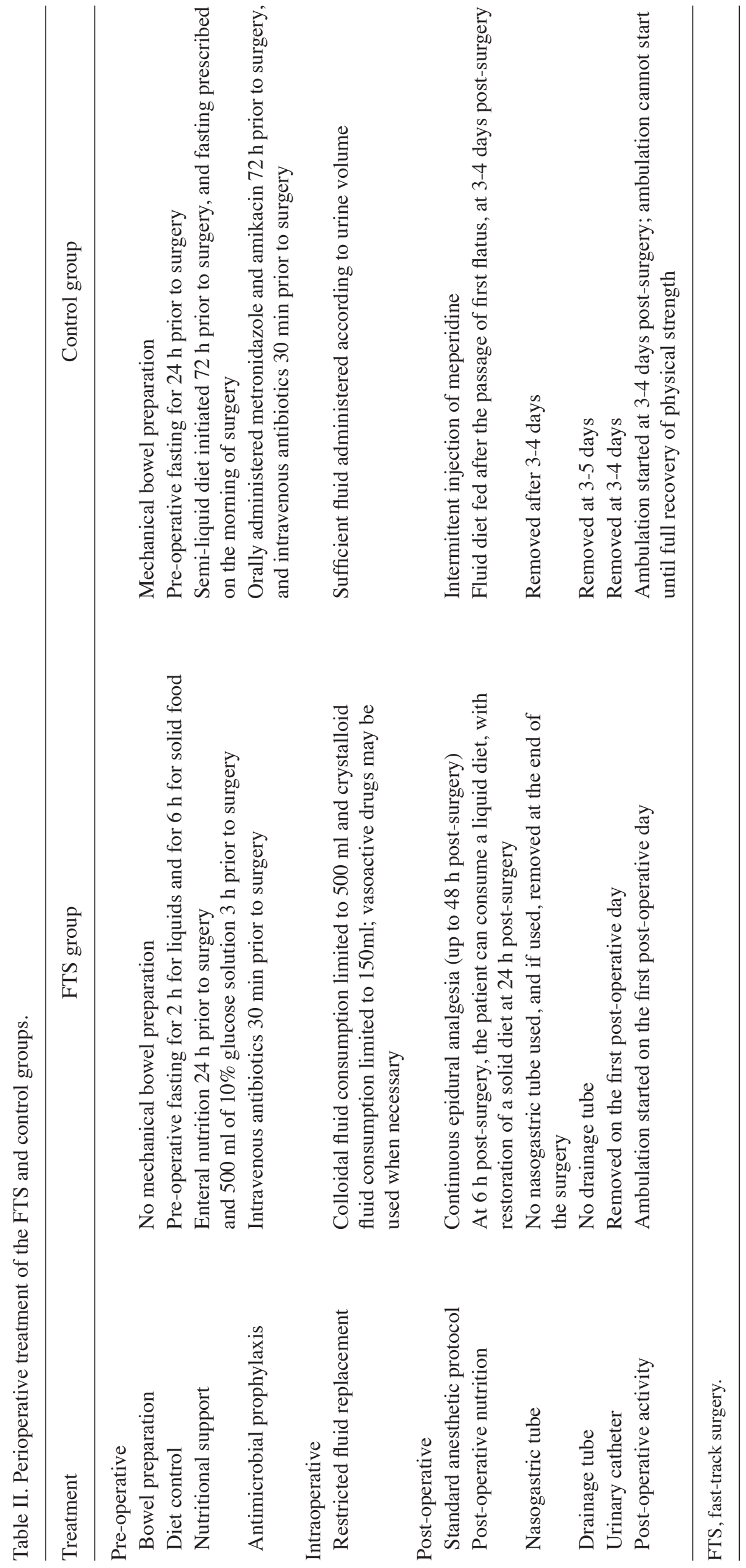


Table III. General information comparison of patients in the FTS and control groups.

\begin{tabular}{|c|c|c|c|}
\hline Parameter & FTS group $(n=31)$ & Control group $(n=39)$ & P-values \\
\hline Age, years $($ mean $\pm S D)$ & $58.5 \pm 8.4$ & $57.4 \pm 10.1$ & 0.629 \\
\hline Gender, n (male/female) & $22 / 9$ & $20 / 19$ & 0.095 \\
\hline Underlying diseases, $\mathrm{n}$ & & & 0.546 \\
\hline Diabetes & 2 & 4 & 0.690 \\
\hline Hypertension & 4 & 9 & 0.357 \\
\hline Heart disease & 0 & 0 & 1.000 \\
\hline Anemia & 4 & 6 & 0.987 \\
\hline TNM staging ${ }^{\mathrm{a}}, \mathrm{n}$ & & & 0.834 \\
\hline Stage I & 1 & 1 & \\
\hline Stage II & 16 & 20 & \\
\hline Stage III & 14 & 18 & \\
\hline Surgical approach, $\mathrm{n}$ & & & 0.984 \\
\hline Right colectomy & 8 & 11 & \\
\hline Transverse colectomy & 1 & 2 & \\
\hline Left colectomy & 2 & 3 & \\
\hline Sigmoid colectomy & 8 & 8 & \\
\hline Anterior resection of the rectum & 12 & 15 & \\
\hline Surgical duration, min $($ mean $\pm \mathrm{SD})$ & $83 \pm 18$ & $88 \pm 15$ & 0.208 \\
\hline Blood loss volume, $\mathrm{ml}($ mean $\pm \mathrm{SD})$ & $14.5 \pm 9.5$ & $16.4 \pm 8.9$ & 0.394 \\
\hline
\end{tabular}

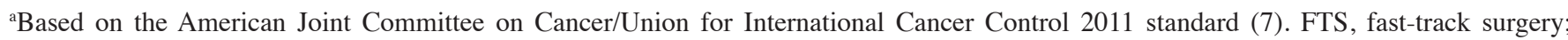
TNM, tumor-node-metastasis; SD, standard deviation.

Table IV. Comparison of FTS and control groups with regard to length of hospital stay and other post-operative parameters.

\begin{tabular}{|c|c|c|c|}
\hline Parameter & FTS group $(n=31)$ & Control group $(n=39)$ & P-values \\
\hline Length of hospital stay, days ${ }^{\mathrm{a}}$ & $5.9 \pm 0.8$ & $10.9 \pm 1.3$ & $<0.001$ \\
\hline Post-operative days ${ }^{\mathrm{a}}$ & $4.3 \pm 0.8$ & $8.0 \pm 1.1$ & $<0.001$ \\
\hline Time until first flatus, days ${ }^{\mathrm{a}}$ & $1.6 \pm 0.8$ & $2.5 \pm 0.9$ & $<0.001$ \\
\hline Time until first defecation, days ${ }^{\mathrm{a}}$ & $2.2 \pm 0.7$ & $4.5 \pm 0.7$ & $<0.001$ \\
\hline Time until resumption of solid diet, days ${ }^{a}$ & $1.1 \pm 0.3$ & $3.6 \pm 0.9$ & $<0.001$ \\
\hline Analgesic administration, n (\%) & & & 0.891 \\
\hline None & $18(58.1)$ & $21(53.9)$ & \\
\hline Once & $5(16.1)$ & $9(23.1)$ & \\
\hline Twice & $6(19.4)$ & $7(17.9)$ & \\
\hline 3 times & $2(6.5)$ & $2(5.1)$ & \\
\hline \multicolumn{4}{|l|}{$\mathrm{CRP}, \mathrm{mg} / \mathrm{l}^{\mathrm{a}}$} \\
\hline Pre-operative & $1.4 \pm 0.9$ & $1.4 \pm 0.90$ & 0.956 \\
\hline Post-operative day 1 & $35.4 \pm 7.5$ & $40.6 \pm 11.9$ & 0.029 \\
\hline \multicolumn{4}{|l|}{ Complications, $\mathrm{n}$} \\
\hline Anastomotic leakage & 0 & 0 & 1.000 \\
\hline Intestinal obstruction & 0 & 2 & 0.502 \\
\hline Wound infection & 1 & 0 & 0.438 \\
\hline
\end{tabular}

${ }^{\mathrm{a}}$ Mean \pm standard deviation. FTS, fast-track surgery; CRP, C-reactive protein.

surgery for colorectal resection can be defined as a coordinated pre-operative approach aimed at reducing surgical stress and facilitating post-operative recovery (8-10).
Stress, as a response to an unpleasant situation, acts as a negative factor and may lead to adverse outcomes in a number of diseases. In contrast to anxiety, stress may provoke certain 
psychological and physiological changes in the body that may result in decreasing activity, increasing prevalence of disease and occasionally, mortality (11). In the present study, CRP level was used as the stress indicator. On post-operative day 1 , the CRP level was significantly higher in the control group compared with that of the FTS group $(\mathrm{P}<0.05)$.

Despite the routine use of mechanical bowel preparation (MBP) in clinic, there is a degree of concern with regard to post-operative complications. For instance, Pineda et al (12) and Bucher et al (13) reported that the application of MBP in colorectal cancer patients was linked with anastomotic leakage and post-operative infectious complications, thus the present study excluded the use of MBP in patients receiving FTS.

Studies suggest that the consumption of carbohydrate-rich drinks prior to surgery facilitates early recovery (14-16). In the present study, the patients in the FTS group underwent a pre-operative fasting period of $2 \mathrm{~h}$ for liquids and $6 \mathrm{~h}$ for solids, while the control group underwent a fasting period of $24 \mathrm{~h}$ prior to surgery. Oral consumption of $500 \mathrm{ml}$ of $10 \%$ glucose solution $3 \mathrm{~h}$ prior to surgery was undertaken by the FTS group, whereas a semi-liquid diet was initiated and fasting was prescribed on the morning of surgery for the control group. However, in a randomized control study, Mathur et al (17) showed that pre-operative carbohydrate loading did not have any benefits for patients undergoing major abdominal surgery. Therefore, pre-operative carbohydrate loading for major surgeries requires further study. It is unclear whether carbohydrate loading played a role in the improved recovery of the FTS group in the present study.

The dietary protocol in the control group undergoing conventional laparoscopic surgery was not easily adapted. The restoration of diet was implemented at 24 h post-surgery, however, the transition from liquid to solid required 3-4 days. Conversely, in the FTS group, the dietary protocol was well tolerated. Furthermore, the early restoration of diet following surgery is also associated with a lower mortality rate (18).

The use of analgesia and the number of complications in the two groups did not differ significantly $(\mathrm{P}>0.05)$. However, the length of hospital stay did differ significantly between the two groups $(\mathrm{P}<0.05)$. This is in agreement with various studies reporting that the implementation of FTS shortens the hospital stay of patients $(19,20)$.

Meta-analyses of control trials and cohort studies have suggested that FTS for colorectal cancer is effective in terms of reducing hospital stay and post-operative pain, and enhancing early recovery following surgery (21-25). Similarly, the present study showed a reduced length of hospital stay and a lower number of post-operative days in the FTS group $(6.7 \pm 1.4$ and $4.1 \pm 0.8$ days, respectively) compared with the control group $(9.2 \pm 2.3$ and $6.4 \pm 1.8$ days, respectively).

In conclusion, FTS has a better outcome compared with conventional surgery for colorectal cancer.

\section{References}

1. Kehlet H: Fast-track colorectal surgery. Lancet 371: 791-793, 2008.

2. Holte K and Kehlet H: Epidural anaesthesia and analgesia - effects on surgical stress responses and implications for postoperative nutirion. Clin Nutr 21: 199-206, 2002.
3. Raue W, Haase O, Junghans T, et al: 'Fast-track' multimodal rehabilitation program improves outcome after laparoscopic sigmoidectomy: A controlled prospective evaluation. Surg Endosc 18: 1463-1468, 2004.

4. Scatizzi M, Kröning KC, Boddi V, et al: Fast-track surgery after laparoscopic colorectal surgery: Is it feasible in a general surgery unit? Surgery 147: 219-226, 2010.

5. Wang G, Jiang ZW, Xu J, Gong JF, Bao Y, Xie LF and Li JS: Fast-track rehabilitation program vs conventional care after colorectal resection: A randomized clinical trial. World J Gastroenterol 17: 671-676, 2011.

6. Wang Q, Suo J, Jiang J, Wang C, Zhao YQ and Cao X: Effectiveness of fast-track rehabilitation vs conventional care in laparoscopic colorectal resection for elderly patients: A randomized trial. Colorectal Dis 14: 1009-1013, 2012.

7. Edge S, Byrd DR, Compton CC, et al (eds). AJCC Cancer Staging Manual. 7th edition. Springer, New York, NY, 2010.

8. Kelley SR, Wolff BG, Lovely JK and Larson DW: Fast-track pathway for minimally invasive colorectal surgery with and without alvimopan (Entereg) ${ }^{\mathrm{TM}}$ : Which is more cost-effective? Am Surg 79: 630-633, 2013.

9. Baek SJ, Kim SH, Kim SY, Shin JW, Kwak JM and Kim J: The safety of a 'fast-track' program after laparoscopic colorectal surgery is comparable in older patients as in younger patients. Surg Endosc 27: 1225-1232, 2013.

10. Sommer T, Larsen JF and Raundahl U: Eliminating learning curve-related morbidity in fast track laparoscopic Roux-en-Y gastric bypass. J Laparoendosc Adv Surg Tech A 21: 307-312, 2011.

11. British Medical Association Health Policy and Economic Research Unit: Work related stress among senior doctors - review of research. London BMA, 2000.

12. Pineda CE, Shelton AA, Hernandez-Boussard T, Morton JM and Welton ML: Mechanical bowel preparation in intestinal surgery: a meta-analysis and review of the literature. J Gastrointest Surg 12: 2037-2044, 2008.

13. Bucher P, Gervaz P, Soravia C, Mermillod B, Erne M and Morel P: Randomized clinical trial of mechanical bowel preparation versus no preparation before elective left-sided colorectal surgery. Br J Surg 92: 409-414, 2005.

14. Nygren J, Thorell A and Ljungqvist O: Preoperative oral carbohydrate nutrition: An update. Curr Opin Clin Nutr Metab Care 4: 255-259, 2001.

15. Ljungqvist $\mathrm{O}$, Nygren $\mathrm{J}$ and Thorell A: Modulation of post-operative insulin resistance by pre-operative carbohydrate loading. Proc Nutr Soc 61: 329-336, 2002.

16. Brady M, Kinn S and Stuart P: Preoperative fasting for adults to prevent perioperative complications. Cochrane Database Syst Rev CD004423, 2003.

17. Mathur S, Plank LD, McCall JL, Shapkov P, McIlroy K, Gillanders LK, Merrie AE, Torrie JJ, Pugh F, Koea JB, Bissett IP and Parry BR: Randomized controlled trial of preoperative oral carbohydrate treatment in major abdominal surgery. Br J Surg 97: 485-494, 2010.

18. Andersen HK, Lewis SJ and Thomas S: Early enteral nutrition within $24 \mathrm{~h}$ of colorectal surgery versus later commencement of feeding for postoperative complications. Cochrane Database Syst Rev: CD004080, 2006.

19. Morończyk DA and Krasnodebski IW: Implementation of the fast track surgery in patients undergoing the colonic resection: Own experience. Pol Przegl Chir 83: 482-487, 2011.

20. Gouvas N, Gogos-Pappas G, Tsimogiannis K, Tsimoyiannis E, Dervenis C and Xynos E: Implementation of fast-track protocols in open and laparoscopic sphincter-preserving rectal cancer surgery: A multicenter, comparative, prospective, non-randomized study. Dig Surg 29: 301-309, 2012.

21. Gouvas N, Tan E, Windsor A, Xynos E and Tekkis PP: Fast-track vs standard care in colorectal surgery: a meta-analysis update. Int J Colorectal Dis 24: 1119-1131, 2009.

22. Wind J, Polle SW, Fung Kon Jin PH, Dejong $\mathrm{CH}$, von Meyenfeldt MF, Ubbink DT, Gouma DJ and Bemelman WA: Laparoscopy and/or Fast Track Multimodal Management Versus Standard Care (LAFA) Study Group; Enhanced Recovery After Surgery (ERAS) Group: Systematic review of enhanced recovery programmes in colonic surgery. Br J Surg 93: 800-809, 2006.

23. Gatt M, Khan S and MacFie J: In response to: Varadhan KK, Neal KR, Dejong CH, Fearon KC, Ljungqvist $\mathrm{O}$ and Lobo DN: The enhanced recovery after surgery (ERAS) pathway for patients undergoing major elective open colorectal surgery: a meta-analysis of randomized controlled trials. Clin Nutr 29 (2010) 434-440. Clin Nutr 29: 689-692, 2010. 
24. Feroci F, Lenzi E, Baraghini M, Garzi A, Vannucchi A, Cantafio S and Scatizzi M: Fast-track surgery in real life: how patient factors influence outcomes and compliance with an enhanced recovery clinical pathway after colorectal surgery. Surg Laparosc Endosc Percutan Tech 23: 259-265, 2013.
25. Feroci F, Baraghini M, Lenzi E, Garzi A, Vannucchi A, Cantafio S and Scatizzi M: Laparoscopic surgery improves postoperative outcomes in high-risk patients with colorectal cancer. Surg Endosc 27: 1130-1137, 2013. 